\title{
A vocação niilista da hermenêutica filosófica de Gianni Vattimo radicada no processo da secularização cristã
}

\author{
The nihilistic vocation of philosophical hermeneutics of Gianni Vattimo \\ rooted in the christian secularization process
}

Omar Lucas Perrout Fortes de Sales*

\begin{abstract}
Resumo
A emergência da hermenêutica filosófica como possível linguagem comum da contemporaneidade provoca a reflexão a debruçar-se sobre o percurso da hermenêutica ao longo de sua gênese e desenvolvimento. 0 presente artigo perfaz tal trajetória, ainda que resumidamente, no intuito de elucidar o estreito vínculo entre hermenêutica e niilismo, bem como situar o pensiero debole do filósofo italiano Gianni Vattimo como expressão da vocação niilista da hermenêutica. Para tanto, destaca-se o papel fundamental desempenhado por Gadamer para o surgimento do que se denomina propriamente hermenêutica filosófica. Lançadas tais bases, propõe-se demonstrar em que medida a hermenêutica filosófica, apregoada por Vattimo como ontologia da atualidade, radica-se junto ao processo da secularização cristã. A secularização cristã contribui para a formação dos traços constitutivos da cultura ocidental. Tais traços permitem a realização de leitura e interpretação da realidade, assim como possibilitam a devida compreensão da importância e centralidade da tradição cristã para a reflexão filosófica contemporânea, sobretudo no tangente à hermenêutica e ao niilismo.
\end{abstract}

Palavras-chave: hermenêutica filosófica; Niilismo; Pensiero debole; Ontologia da atualidade; secularização cristã.

\begin{abstract}
The emergence of philosophical hermeneutics as the possible common language of contemporaneity forces us to reflect on the path of hermeneutics from its genesis and through its development. This article briefly covers this trajectory, in order to elucidate the close relationship between hermeneutics and nihilism, as well as place the "weak thinking" (pensiero debole) of the Italian philosopher Gianni Vattimo as the expression of the nihilistic vocation of hermeneutics. Therefore, the article highlights the key role played by Gadamer in the emergence of what is properly called philosophical hermeneutics. From these foundations, it is intended to demonstrate the extent to which philosophical hermeneutics, rended by Vattimo as the Ontology of Actuality, finds its roots in the Christian secularization process. Christian secularization contributes to form some of the traits of the Western culture. These traits allow both the reading and interpretation of reality as enable a proper understanding of the importance and centrality of the Christian tradition to contemporary philosophical reflection, especially with regards to hermeneutics and nihilism.
\end{abstract}

Keywords: philosophical hermeneutics; Nihilism; "Weak thinking" (pensiero debole); Ontology of Actuality; Christian secularization.

Artigo submetido em 12 de fevereiro de 2015 e aprovado em 27 de setembro de 2015.

* Pós-doutor pela Universitat de Barcelona, doutor e mestre em Teologia pela FAJE. País de origem: Brasil. E-mail: omarlucass@hotmail.com 


\section{Introdução}

Rápidas e constantes transformações sociais, políticas, religiosas e culturais afetam a realidade e caracterizam o período atual como um período de crise. Reconfiguram o modo de o ser humano compreender-se e relacionar-se com o mundo e consequentemente abalam o universo de seguranças objetivas agora transpostas em uma plêiade de múltiplas nuances e indeterminações.

As pretensões totalizantes da razão, legitimadas pela modernidade, cada vez mais cedem espaço à diversidade de narrativas a desenhar o cenário de perda dos referenciais fundamentais. $\mathrm{O}$ desencanto perante a exaltada razão absoluta, bem como a proclamada morte de Deus, situam o ser humano diante da ausência de paradigma único e da possibilidade de retorno ao distante porto seguro. A verdade objetiva vê-se esfacelada em pequenos relatos e as diversas representações da realidade fragmentam o universo de sentidos a tecer cenário cada vez mais complexo e ambíguo. O ser humano, por sua vez, percebe-se envolto pelo emaranhado de incertezas e inseguranças a gerar profunda crise de sentido, marcada pela angústia de viver e pela crescente onda niilista.

Em meio a esse cenário destaca-se o pensamento do italiano Gianni Vattimo (1936), um dos maiores filósofos da atualidade, o qual compõe o rol dos teóricos do fim da metafísica ao apregoar uma filosofia da interpretação do enfraquecimento do ser, por meio da qual elucida e discute os principais traços constitutivos da cultura contemporânea. Filósofo precursor do pensiero debole ${ }^{1}$, categoria interpretativa da cultura ocidental no momento atual, reflete sistematicamente o fato de a pretensão metafísica da existência de absolutos - como verdade e razão assolada pela crise da modernidade, cada vez mais ceder espaço a diversas

\footnotetext{
${ }^{1}$ Opta-se por manter a expressão pensiero debobe no original italiano (comumente traduzida no Brasil por pensamento fraco), no intuito de se evitar o risco da contraposição de uma razão forte da modernidade ao "pensamento fraco" pós-moderno. Isto porque não se trata de afirmar a fraqueza ou a incapacidade da razão, o que comprometeria as condições de possibilidade do fazer filosófico, bem como as tentativas de desenvolvimento das ciências. Antes, o pensiero debole propõe o reconhecimento da transitoriedade, da impermanência, dos fluxos constantes de ideias e interpretações, assim como das aventuras do pensamento vividas às voltas com a realidade que se dá historicamente.
} 
interpretações da realidade em constante conflito.

A ontologia hermenêutica proposta por Vattimo, levada a cabo como ontologia da atualidade, possibilita a compreensão das mudanças em curso e constitui grande esforço intelectivo de diagnóstico e análise da situação presente. Uma vez que a Filosofia tem hodiernamente passado à margem da problematização do papel da herança cristã a tecer e compor a cultura ocidental, o presente artigo objetiva resgatar a centralidade de tal tarefa para o fazer filosófico, a fim de iluminar a compreensão da paradoxal situação em que a vocação niilista da hermenêutica desenvolvida por Vattimo encontra-se imbricada junto aos veios da secularização cristã.

Assim sendo, propõe-se breve desenvolvimento da filosofia hermenêutica desde seus primórdios como teoria de interpretação de textos. Na sequência, a demarcação do momento do nascimento da filosofia hermenêutica na Europa Continental implica situar os precursores de tal corrente de pensamento comprometido com a afirmação da verdade advinda de instâncias a extrapolar a experiência metódica ou científica da realidade. Como passo subsequente, propõese a abordagem da célebre afirmação de Vattimo segundo a qual a hermenêutica é compreendida como koiné da filosofia e da cultura. Com estes pressupostos devidamente explicitados, tem-se edificada a base sobre a qual o pensiero debole emerge enquanto fruto de uma trajetória filosófica às voltas com o destino do ser e da metafísica.

Em meio à reflexão de cunho marcadamente filosófico, o texto culmina por inserir o papel fundamental exercido pelo processo de secularização cristã junto ao desenvolvimento de uma concepção hermenêutica regida pelo crivo do niilismo e pelo destino de enfraquecimento do ser. Constatar e problematizar tal nexo constitui originalidade de um pensamento aberto à pluralidade e tanto menos violento por não se ater à objetividade de um princípio único e fundacional. Aqui se insere a oportunidade de se repensar, desde outro olhar, o legado da secularização cristã para a cultura ocidental. 


\section{Percursos da hermenêutica}

Etimologicamente a palavra hermenêutica remete ao deus Hermes da mitologia grega, o mensageiro intérprete das mensagens ocultas presentes junto aos caminhos e encruzilhadas. Mensagens estas, dotadas de ambiguidade e carência de um sentido claro para os transeuntes. Hermes se situa justamente onde duelam a falta de clareza e a lucidez, em meio às sendas marcadas pela ausência de direcionamento unívoco. Daí o fato de a hermenêutica nascer como arte de explicar, traduzir ou interpretar textos, na busca pelo significado ou sentido oculto das palavras, da mensagem. A Hermes também se atribui a origem da linguagem e da escrita, de íntima conexão com a hermenêutica nascente. Para além da mitologia, os pré-socráticos já exerciam o papel de hermeneutas na interpretação da literatura homérica (BEUCHOT; ARENAS-DOLZ, 2008, p. 23). Platão, por sua vez, não via com bons olhos os hermeneutas, pois considerava relativista sua interpretação, assim como atribui tal adjetivo aos sofistas, aos quais também dirige críticas².

$\mathrm{Na}$ esteira da concepção mítica de Hermes, os germes antecessores da hermenêutica filosófica remetem à ideia e ao conceito derivado da interpretação dos textos clássicos (hermenêutica literária); dos textos bíblicos (hermenêutica bíblica) e dos cânones e textos legislativos (hermenêutica jurídica). Desse modo, especificamente o que se formula originariamente por hermenêutica encontra-se atrelado à interpretação dos textos dessas três áreas. Donde se pode afirmar que embora o termo hermenêutica tenha sido apropriado tardiamente pela filosofia, sua conceituação e uso apresentam raízes remotas:

Hermenêutica (do grego hermenéia = interpretação) designa a arte, a técnica de interpretação (ars interpretandi) e suas respectivas regras (regulae interpretandi), que servem de guia para a arte de interpretar os textos clássicos (hermenêutica literária), os textos bíblicos (hermenêutica bíblica), os cânones e os textos legislativos (hermenêutica jurídica). O

\footnotetext{
2Para se contextualizar a hermenêutica ao longo de seu desenvolvimento histórico inicial considerar: BEUCHOT; ARENAS-DOLZ, 2008, p. 21-30, capítulo I intitulado Hermenéutica.
} 
termo grego 'hermenêutica' aparece um tanto tardiamente, entre os séculos XVI e XVII, para substituir o termo latino interpretatio, mas a teoria patrística do sentido literal e do sentido alegórico da Escritura, a teoria medieval dos quatro sentidos da Escritura, a teoria da Reforma da Scriptura sui ipsius interpres (a Escritura é o intérprete de si mesma) já são teorias hermenêuticas propriamente ditas. (GIBELLINI, 2002, p. 57$58)$.

Esses foram os campos iniciais de atuação e difusão de modo específico de ler e interpretar textos, na busca de legitimação da ação de se compreender e se apropriar, por meio da linguagem, dos conteúdos expressos por autores clássicos e por textos caros à cultura e à sociedade.

Segundo a clássica definição de Paul Ricoeur, a hermenêutica consiste na ciência e na arte de interpretar textos (RICOEUR, 1995, p. 82)3. O leitor desempenha o papel de hermeneuta diante do texto e da intencionalidade do autor, de modo a realizar um movimento dialético entre as partes em jogo a fim de obter o significado mais profundo do conteúdo em questão, num exercício de superação dos dados aparentes e superficiais, o que converte a hermenêutica na arte de garimpar e lapidar o(s) contexto(s), uma vez que considera o mundo do autor, o conjunto de metáforas históricas utilizadas, o significado sintático, semântico e pragmático dos termos intencionalmente escolhidos pelo autor, levando-se em conta o problema das traduções, a contextualização histórica, bem como a presença de elementos implícitos e explícitos a permear o texto. Cabe ressaltar a influência fenomenológica de Husserl no pensamento de Ricoeur, mesma influência a marcar o pensamento heideggeriano, no qual se situam os germes do que posteriormente se desenvolverá como hermenêutica filosófica propriamente dita.

Ainda que a hermenêutica ganhe vigor como interpretação dos textos clássicos, enquanto hermenêutica filosófica é com Verdade e método de Gadamer que se tem o ponto de partida incontestável desta corrente de pensamento. Por ocasião desta publicação (1960), a hermenêutica ainda era um termo específico

\footnotetext{
${ }^{3}$ Os esforços hermenêuticos de Paul Ricoeur conduzem à elaboração de um método de interpretação e análise dos textos bíblicos a convergir na difundida teologia narrativa (RICOEUR, P. Vers une théologie narrative: sa nécessité, ses ressources, ses difficultés. In: RICOEUR, P. L'herméneutique biblique. Paris: Du Cerf, 2001. p. 326-342).
} 
que designava a interpretação de textos e carecia de formulação teórica no plano estritamente filosófico. Em consonância com o pensamento de Heidegger, Gadamer realiza tal empreitada. Segundo conhecida tese de Habermas, Gadamer urbaniza o pensamento de Heidegger, ou seja, o torna transitável, abre vias pelas quais se podem chegar mais facilmente até ele.

Não obstante a contribuição de Gadamer, Vattimo faz uma ressalva: "Na urbanização à qual [...] Gadamer submeteu o heideggerianismo, perdeu-se (ou de qualquer forma ficou em segundo plano) uma parte essencial: a concepção heideggeriana da metafísica como história do ser" (VATTIMO, 1991, p. 68). Ademais, Gadamer não compartilha da crítica de Heidegger à metafísica grega; antes desfere crítica à redução da verdade ao campo do método científico-positivo, redução presente ao longo dos séculos XVIII e XIX4 4 . Desse modo, para o filósofo italiano, Verdade e método propõe conclusões pouco radicais no tangente à concepção da situação da civilização tecno-científica moderna.

Para Vattimo, os intérpretes e os seguidores de Heidegger não desenvolveram suficientemente sequer os primeiros elementos para uma ontologia do declínio (uma ontologia do reconhecimento de que não se pode mais pensar o ser por meio de estruturas fortes do pensamento ou como fundamento). Para além da crítica de Vattimo a Gadamer, o filósofo italiano exalta que a exceção a essa afirmação recai sobre alguns aspectos da hermenêutica gadameriana por meio da difundida tese segundo a qual o ser que pode ser compreendido é linguagem, tese a exaltar a abertura histórica do ser. De modo geral, a ausência da ontologia do declínio na escola heideggeriana se deve provavelmente ao fato de os seus representantes ainda insistirem em uma leitura de direita, a qual segue pensando o ser em termos de fundação e objetividade.

Elucidar o que Vattimo compreende por hermenêutica permite melhor situar a crítica a Gadamer, bem como vislumbrar o percurso que se abre a partir de

\footnotetext{
${ }^{4}$ Aqui se situa grande crítica ao kantismo, ao qual se atribui ter desempenhado papel decisivo para tal redução.
} 
tal compreensão. Para Vattimo pode se considerar dúplice sentido de hermenêutica:

1- Arte de interpretar textos. Sentido mais tradicional decorrente da ideia de uma correta interpretação dos textos e, desse modo, a apresentar dimensão considerada prática.

2- Posição filosófica ou teoria filosófica da interpretação que se desenvolve a partir da segunda metade do século XX na Europa Continental, a partir de Heidegger, a qual privilegia a interpretação a partir do crivo ontológico.

Para a filosofia de Vattimo importa a segunda definição, a qual comporta implicitamente a necessidade de se manter a fidelidade a Heidegger no tangente à compreensão da história do Ocidente como história da metafísica, esta compreendida como história do esquecimento do ser (HEIDEGGER, 2012, p. 42).

Enquanto linha de pensamento nomeada hermenêutica filosófica, cabe ainda aprofundar uma distinção para que não se caia na malha de equívocos. A hermenêutica filosófica pode significar a arte de interpretar textos filosóficos (assim como a hermenêutica bíblica ou jurídica), ou ainda teoria filosófica da interpretação. Aquela remete a conjunto de regras e práticas de interpretação no sentido aristotélico de téchne; esta remete à análise filosófica da questão da interpretação (VATTIMO, 1986, p. 6).

Em síntese, pode se dizer que a hermenêutica é a filosofia que se desenvolve a partir do eixo Heidegger e Gadamer. Nasce como esforço de responder à crise do pensamento europeu e à crise da própria razão, decorrentes da experiência do pósguerra. O golpe desferido à primazia da razão pelos chamados mestres da suspeita também compõe este cenário. A filosofia hermenêutica intenta responder a tal crise por meio da afirmação da possibilidade da verdade advinda da experiência de outras instâncias, como da obra de arte e da historicidade (VATTIMO, 1995, p. 38). Aqui se situa o desafio de a hermenêutica se compreender a si mesma como a teoria da estrutura interpretativa da existência humana. Nessa perspectiva, se 
insere o esforço de Verdade e método ao afirmar a legitimidade da experiência extra-científica, extra-metódica e, desse modo, a questionar diretamente o cientificismo (GADAMER, 2012, p. 21; VATTIMO, 1991, p. 65-66). Dentre as fontes das quais Vattimo se nutre, vale ressaltar o papel central desempenhado por Luigi Pareyson como grande mestre junto à Universidade de Torino e amigo de toda a vida. Na vertente italiana, coube a Pareyson desenvolver a experiência da verdade como experiência interpretativa (VATTIMO; PATERLINI, 2006, p. 38-39, 126)5. Vattimo se incumbiu da tarefa de latinizar a hermenêutica, ao traduzir Verdade $e$ método (1972) e introduzir o pensamento de Gadamer na Itália, bem como desenvolvê-la para além da raiz anglo-saxônica (REALE, 2012, p. VII) ${ }^{6}$.

$\mathrm{Na}$ dinâmica gadameriana, a hermenêutica advém do posicionamento antimetafísico de Heidegger ao contrapor à verdade objetiva e à existência do fundamento, a afirmação da historicidade e dimensão de abertura característica do ser humano enquanto sujeito cuja compreensão de si e do mundo é o próprio modo de ser do ser humano.7 Ou seja, o homem em seu ser-no-mundo é constitutivamente compreensão da existência. Ao contrário do ser humano, as coisas dispostas no mundo não compreendem sua existencialidade, tampouco a sua possibilidade de vir-a-ser. A dimensão de projetualidade é própria do ser humano, como expressa a analítica existencial de Heidegger e bem desenvolve a fenomenologia hermenêutica. Assim sendo, ilumina-se a conclusão segundo a qual a hermenêutica não se condensa em mera explicação de textos, antes contempla o modo de se dar a relação do ser humano com o mundo. Nessa perspectiva, Vattimo propõe interpretação do significado filosófico da hermenêutica e atesta o lugar central por ela exercido, como se desenvolve a seguir.

\footnotetext{
${ }^{5} \mathrm{Em}$ 1964, indicado por Pareyson, Vattimo assume a cadeira de Estética da Universidade de Torino. A reflexão hermenêutica de Vattimo, isto inclui a formulação do pensiero debole, se encontra imbricada às intuições estéticas presentes em seus escritos ao longo da década de 1960 e 1970, quando o autor ainda que atrelado à herança de Heidegger, desta se distancia ao propor a reflexão sobre a verdade da arte como estética ontológica.

${ }^{6}$ Tradução esta aprovada pelo próprio Gadamer e por ele aclamada como a melhor realizada de seu texto.

${ }^{7}$ Postura de contestação da metafísica foi adotada por autores como Emmanuel Lévinas (2000), influenciado por Heidegger, para o qual importa romper com a lógica da metafísica tradicional a partir da alteridade a evocar a ruptura com a ordem violenta e totalitária dos sistemas dominantes. Trata-se da proposição de novo paradigma "metafísico" protagonizado pelo advento da alteridade mediante o clamor expresso no olhar do outro.
} 


\section{A hermenêutica como koiné da filosofia e da cultura}

"A hermenêutica se compromete historicamente e compreende seu próprio objetivo em termos radicalmente não transcendentais" (VATTIMO, 1991, p. 70).

Ao se debruçar sobre o fenômeno da difusão da hermenêutica, Vattimo a afirma como koiné da filosofia e da cultura dos anos 1980 (VATTIMO, 1991, p. 201). Tal constatação se converte no ponto de partida para se questionar sobre o significado da hermenêutica para a filosofia. A tese do autor sustenta que se os anos 1950 e 1960 foram marcados pela hegemonia do marxismo e os 1970 pelo estruturalismo, nos anos 1980 se existe um “idioma” comum dentro da filosofia e da cultura, este idioma é a hermenêutica (VATTIMO, 1991, p. 57).

Com isto, Vattimo advoga que depois da hegemonia estruturalista a hermenêutica melhor responde à exigência historicista advinda da crise do estruturalismo, bem como às demandas da crise da metafísica. Um dos fatores que conduzem o estruturalismo a alcançar seu esgotamento, situa-se no fato de este não mais corresponder à necessidade de diálogo da cultura ocidental (leia-se eurocentrismo) com outras culturas. Em contrapartida, a hermenêutica assume o lugar central por melhor contestar aos problemas contemporâneos (VATTIMO, 1991, p. 55-56).

A afirmação de Vattimo (1995, p. 38) leva em conta os horizontes abertos também por Nietzsche: "não existem fatos, somente interpretações”, bem como o anúncio da "morte de Deus". Afirmar com Nietzsche que não existem fatos, somente interpretações expressa a íntima relação entre ausência de objetividade e o caráter interpretativo da experiência. Tais anúncios/formulações abriram veredas para a assunção de novas e não metafísicas formas de pensar, no caso a hermenêutica, assim como para sua consolidação e pertinência como linguagem comum da filosofia e da cultura.

A morte de Deus, por sua vez, não pode ter sido proferida por Nietzsche enquanto a mera não existência de Deus. Isso porque, tal afirmação implicaria a 
imposição de outra verdade absoluta: Deus não existe. Assim sendo, ainda significaria oferecer algum fundamento à realidade, o que se resolveria na inversão do polo de tensão. O reconhecimento da morte de Deus demanda a afirmação da ausência de fundamento único a nortear a realidade. De outro modo, a hermenêutica não ensina que Deus não existe; ensina que a experiência humana foi transformada de tal modo que já não se pode mais conceber verdades últimas objetivas, pois o que se tem agora são apelos e anúncios. Ao explicitar o significado da morte de Deus, Vattimo esclarece:

Em tantos sentidos que não podem ser com facilidade reunidos em um conjunto sistemático, mas que, creio eu, estão bem claros, é exatamente este o mundo no qual o 'Deus moral', isto é, o fundamento da metafísica morreu e foi enterrado. Todavia, este é justamente aquele que Pascal chamava de Deus dos filósofos e, de fato, muitos são os sinais que parecem indicar que foi a própria morte deste Deus o que abriu caminho para uma vitalidade renovada da religião. (VATTIMO, 2004, p. 24).8

A hermenêutica filosófica, ancorada na despedida ou no adeus às estruturas fortes do ser, contempla a busca da emancipação da autonomia do sujeito. Se por um lado esta é a tarefa da filosofia, por outro, há de ser também a tarefa da hermenêutica que, ao se converter em koiné da filosofia e da cultura há de retomar a inspiração originária presente na meditação heideggeriana sobre a metafísica e seu destino. Duas décadas depois, logo no início dos anos 2000, Vattimo ainda alude à relevância da hermenêutica como koiné:

Propus falar, a propósito da cultura - não só filosófica - do mundo ocidental, tardo-industrial, pós-moderno, que é o nosso, de uma koiné hermenêutica. Como todas as pré-compreensões hermenêuticas, também esta é uma imagem vaga, que parece muito marcada por uma espécie de impressionismo filosófico-sociológico; para muitos parece, com alguma razão, uma generalização ambiciosa em demasia, que unifica uma multiplicidade de fenômenos totalmente heterogêneos. Todavia, assumir o risco de concentrar a atenção sobre a koiné hermenêutica como característica global, e vaga, da nossa cultura atual é indispensável para qualquer compreensão teórica não superficial da mesma, capaz de alcançar um fio condutor interpretativo. (VATTIMO, 2001, p. 22-23).

\footnotetext{
${ }^{8} \mathrm{Em}$ outra passagem Vattimo ressalta que Nietzsche e Heidegger foram decisivos para os passos iniciais da filosofia hermenêutica, pois "[...] antes de Heidegger, e de Nietzsche, a história do pensamento oferece somente outro exemplo decisivo, de uma teorização da fundamentação hermenêutica. Tal exemplo é a dedução kantiana dos juízos de gosto presente na Crítica do juízo" (VATTIMO, 1989, p. 59).
} 
A hermenêutica filosófica desenvolvida por Vattimo, compreendida como koiné do tempo presente, apresenta a peculiaridade do acento niilista que a caracteriza e constitui a original contribuição do autor para o debate contemporâneo.

\section{A vocação niilista da hermenêutica}

No intuito de abordar a relação entre o niilismo e a hermenêutica, compete de antemão delimitar o que Vattimo denomina niilismo. Pelo fato de tal termo comportar ambiguidades e apresentar variantes quanto à sua interpretação pela tradição filosófica, cabe ressaltar como o filósofo compreende e emprega tal termo.

Vattimo situa o niilismo no "sentido assinalado de modo inaugural por Nietzsche: a dissolução de cada fundamento último, a consciência de que, na história da filosofia, e da cultura ocidental de modo geral, 'Deus morreu' e 'o mundo verdadeiro tornou-se fábula"” (VATTIMO, 2003, p. 5). Desse modo, a raiz do niilismo reside na superfluidez dos valores últimos abordada por Nietzsche mediante a afirmação da morte de Deus e por Heidegger, em sentido aproximado, como o esquecimento do ser e sua redução a valor de troca (VATTIMO, 2002, p. 45). Ambos os autores convergem, na compreensão de Vattimo, ao afirmar não o desaparecimento dos valores tout court, mas dos valores supremos, resumidos precisamente no valor absoluto Deus (VATTIMO, 2002, p. 6). A morte de Deus (Nietzsche) possibilita e compõe o cenário do fim da metafísica (Heidegger) e ambos favorecem a emergência do niilismo na cultura ocidental, interpretado por Vattimo sob o crivo hermenêutico do pensiero debole.

Assim sendo, Vattimo define explicitamente o niilismo:

Niilismo significa, aqui, o mesmo que significa para Nietzsche na nota que se encontra no início da velha edição da Wille zur Macht: a situação em que o homem rola do centro para X. Mas niilismo, nessa acepção, também é idêntico ao definido por Heidegger: o processo em que, no fim, do ser como tal 'nada mais há'. (VATTIMO, 2002, p. 3-4). 
A metáfora "rolar do centro para X" implica o desnorteamento do referencial, o deslocamento do eixo central agora transferido para o periférico e o marginal. Nessa perspectiva, o niilismo advém do processo de transição do centro à periferia, da atribuição de protagonismo às aparências e da destituição do valor do ser. Daí, Deus morre quando o saber não tem mais necessidade de chegar às causas últimas e se arrefece a crença em uma alma imortal, no céu, no inferno, numa ordem objetiva e definitiva a significar e garantir toda a realidade. "O niilismo é, portanto, a situação de desorientamento que emerge uma vez que diminuem as referências tradicionais, isto é, os ideais e os valores que respondiam à pergunta ao 'por quê' e, desse modo, iluminavam o agir do homem" (VOLPI, 2009, p. 4).

Em linhas gerais, Vattimo distingue duas posturas fundamentais relativas ao modo pelo qual o ser humano e a sociedade/cultura se posicionam perante o niilismo: a negação ou o reconhecimento positivo do niilismo como oportunidade, o que caracteriza respectivamente o niilismo reativo e o niilismo consumado.

O niilismo reativo indica a atitude de nostalgia, paralisia e ressentimento em face dos ideais da razão forte da modernidade. Tem a marca do profundo saudosismo da verdade absoluta. Qualifica o posicionamento de governos e instituições atrelados à defesa e à busca do retorno do poder de outrora. Paralisa a reflexão, justamente por se alimentar da negação da memória enfraquecida/desfalecida do ser que já não se dá historicamente como antes, quando se ancorava, no caso da religião, a uma ordem dita natural do mundo. Compõe o cenário de crise enquanto lhe falta qualquer base possível de retomada dos fundamentos e liga-se negativamente à morte de Deus e ao fim da metafísica.

Por sua vez, o niilismo consumado expressa a assunção positiva do fim dos valores supremos.9 Imagem frequente nos textos de Nietzsche compreende o niilismo como a única chance, pois o niilismo é tudo o que se pode alcançar.

${ }^{9}$ Nichilismo compiuto (niilismo consumado) nos textos originais de Vattimo. O verbo italiano compiere utilizado pelo autor procede do latim complere (preencher, completar, cumprir a promessa) e significa positivamente realizar, alcançar o fim, atingir o termo. 
Vattimo se posiciona em sintonia com essa última concepção e constata o fato de a pós-modernidade favorecer a emergência de niilistas consumados, uma vez que a cultura do século XX caracteriza-se pelo fim dos projetos de reapropriação (VATTIMO, 2002, p. 3-4). Ao reconhecer a relevância da crítica de Nietzsche e de Heidegger, Vattimo privilegia o niilismo consumado, configurado pela atitude de assunção do fim dos valores supremos, no intuito de daí se extrair os pressupostos necessários ao distanciamento crítico do que tem sido o pensamento ocidental desde a aurora da filosofia - pensamento do fundamento (VATTIMO, 2002, p. VVI).

No tangente à pós-modernidade, Vattimo esclarece:

O pós de pós-moderno indica, com efeito, uma despedida da modernidade, que, na medida em que quer fugir das suas lógicas de desenvolvimento, ou seja, sobretudo da ideia da 'superação' crítica em direção a uma nova fundação, busca precisamente o que Nietzsche e Heidegger procuraram em sua peculiar relação 'crítica' com o pensamento ocidental. (VATTIMO, 2002, p. VII).

Nessa perspectiva, o filósofo qualifica a pós-modernidade como a constatação da dissolução dos projetos da modernidade. Vattimo considera o "pós" de pós-moderno no sentido de despedida e não continuação ou exacerbação da modernidade. Assim sendo, contrapõe-se a Gilles Lipovetsky, o qual define a época atual a partir da noção de hipermodernidade:

A expressão 'pós-moderno' é ambígua, inapropriada e, para dizer a verdade, errada. Para ser claro, não há sociedade pós-moderna, assim como não há indivíduos pós-modernos. Presenciamos o advento de uma sociedade e de um indivíduo hipermodernos. Não estamos depois da modernidade, estamos numa segunda modernidade, e vivemos uma nova revolução moderna que traz uma nova aventura da autonomia dos indivíduos. (LIPOVETSKY, 2009, p. 59).

Já em 1979 Jean François Lyotard (2002, p. XVI) publicava A condição pósmoderna, na qual apresenta o pós-moderno como "a incredulidade em relação aos metarrelatos". Ainda que tenha influenciado sobremaneira toda a tradição filosófica posterior a refletir sobre a pós-modernidade, a afirmação expressa da 
perda dos metarrelatos incorre o risco de conduzir necessariamente a outra ordem metafísica: a inexistência dos grandes relatos. Justamente por isto Vattimo prefere conceber essa "perda” não como algo concluído, já instaurado, mas como processo contínuo de enfraquecimento e de debilitação das estruturas fortes do ser: "O que significa afirmar que os 'metarrelatos' foram invalidados senão propor novamente um 'metarrelato"'? (VATTIMO, 1991, p. 18).

O niilismo como única chance não defende o "fim da história" ou o "fim da filosofia”, antes traduz oportunidade de reconstrução filosófica e de questionamento da lógica do desenvolvimento e da busca do sempre novo, próprias da concepção moderna e agora "dissolvida" pela pós-modernidade. Configura-se mediante o apelo ao abandono do porto seguro. Na contramão desta vertente, o niilismo reativo nega qualquer valoração positiva do niilismo e considera tal negação extremamente positiva. Ao defender o niilismo consumado, Vattimo exalta o reconhecimento e a afirmação da positividade presente no niilismo. Nessa perspectiva, tal niilismo emerge como última chance, a única possibilidade.

O niilista reativo, como se pode constatar, se recusa a tomar conhecimento do aniquilamento dos valores objetivos e utiliza ideologias culturais, políticas, religiosas e estéticas a fim de sanar e recuperar o fundamento perdido:

A ligação entre passividade e reatividade mostra-se, assim, clara: a reação, ou seja, a invenção de todo tipo de disfarces, de máscaras ideológicas, é um aspecto da atitude que se recusa a reconhecer que não existem significados e valores objetivos, estruturas dadas do ser, e que por isso seria preciso criá-los ativamente. O niilista passivo passa à margem dessa tarefa criativa, e reage usando disfarces e máscaras que devem preencher o vazio das estruturas objetivas dadas. (VATTIMO, 2010, p. 242-243).

Desse modo, o niilista reativo atribui ao mundo verdadeiro o caráter de fábula (em sintonia com a crítica nietzschiana) e a esta concede a antiga dignidade metafísica. Vattimo se opõe a essa perspectiva e justamente nesse ponto, o niilismo aparece como sendo a "única" chance, por isso sintetiza: "o que acontece hoje em 
relação ao niilismo é o seguinte: começamos a ser, a poder ser, niilistas consumados" (VATTIMO, 2002, p. 3). De modo conclusivo, ao final só nos resta o niilismo.

Em consonância com a valoração positiva do niilismo emerge a expressão pensiero debole como expressão e "encarnação" mais fiel da hermenêutica filosófica de cunho niilista. Nessa perspectiva, a ideia central da obra de Vattimo reside na constatação de que a continuidade da filosofia encontra-se atrelada ao pensiero debole (RISSER, 2007, p. 217), bem como à concepção hermenêutica da qual provém, como se explicita a seguir.

\section{0 pensiero debole como expressão da vocação niilista da hermenêutica}

Se disséssemos que o limite entre "o que vale" e o que não vale nestas experiências está marcado por sua maior ou menor fidelidade ao fio condutor do niilismo (redução da violência, enfraquecimento das identidades fortes e agressivas, aceitação do outro), não interpretaríamos fielmente o sentido da vocação niilista da hermenêutica?(VATTIMO, 1995, p. 120).10

Para aludir ao "desaparecimento" ou à redução dos valores absolutos, a partir de Nietzsche e de Heidegger, Vattimo utiliza a expressão pensiero debole. Carlo Augusto Viano foi o primeiro a utilizar a expressão ragione debole, da qual Vattimo quase copiou pensiero debole, conforme este atesta em sua autobiografia (VATTIMO; PATERLINI, 2006, p. 115). Vattimo emprega a expressão pela primeira vez durante o outono de 1979 em conferência proferida numa pequena galeria de arte de Salermo. Tal conferência foi publicada em 1983 como primeiro ensaio do livro intitulado Il pensiero debole, escrito em parceria com Pier Aldo Rovatti (VATTIMO; ROVATTI, 1983).11

\footnotetext{
10"Nestas experiências" Vattimo se refere ao conjunto de fenômenos de identificação e pertença à comunidade, presente em determinadas formas de arte jovem, como concertos de rock, bem como entre seguidores do mesmo tipo de música, como o punk.

${ }^{11}$ Título do referido ensaio: Dialettica, differenza, pensiero debole, p. 12-28.
} 
A formulação do pensiero debole foi motivada, em grande medida, por motivos éticos e religiosos a partir da constatação da impossibilidade de se produzir um princípio absoluto. A justificação política e ideológica do pensiero debole se encontra na obra $O$ sujeito e a máscara (1974), enquanto manifesto filosófico-político para a nova esquerda democrática italiana, para os grupos que não somente buscavam mudar as relações de poder, mas também a própria estrutura do sujeito (ZABALA, 2007a, p. 21). O livro foi alvo de interpretações errôneas pela esquerda e pelos estudantes ativistas e instigou Vattimo a buscar esclarecer o problema conceitual gerado, uma vez que tais grupos se mantinham ainda atrelados à subjetividade retórica e metafísica.

Uma distinção faz-se necessária: niilismo, morte de Deus e fim da metafísica, são termos advindos de Nietzsche e de Heidegger. Já pensiero debole, é uma noção específica de Vattimo, ou seja, a valoração positiva do niilismo e, portanto, uma proposta com a qual nem Nietzsche nem Heidegger seguramente concordariam, já que ambos, de maneiras diversas, auguram uma superação do niilismo (não apenas o reativo). No caso de Heidegger, em particular, pode-se dizer certamente que toda experiência é interpretativa. Heidegger não encara esse fato como Vattimo, antes ao contrário. Quer dizer, para Vattimo nenhuma interpretação detém a verdade, ao passo que para Heidegger, segundo sua ideia de fenomenologia hermenêutica, de certo modo, toda interpretação é verdadeira. Por sua vez, Vattimo compartilha da tese de Heidegger, segundo a qual se estabelece crítica à noção da verdade como adequação ou conformidade da proposição às coisas (VATTIMO, 1995, p. 124-125).

Os princípios filosóficos sobre os quais se assenta a ontologia hermenêutica de Gianni Vattimo têm na formulação do pensiero debole, enquanto horizonte de compreensão da pós-modernidade, a fonte de inspiração mais original do pensamento do autor. Aqui reside a grande contribuição de Vattimo para a filosofia contemporânea, bem como para as ciências humanas de modo geral. 
O pensiero debole caracteriza-se por exaltar a multiplicidade de interpretações acerca da realidade, os diversos relatos que se opõem à violência da objetividade metafísica, bem como a fragmentação da verdade, traços característicos da pós-modernidade. Por isso, aqui se compreende que antes de impossibilitar a acolhida do novo, o pensiero debole a preconiza e a promove. "Dessa forma, o pensamento fraco é a emancipação da autonomia, porque nos ajuda a compreender ou, ao menos, duvidar de nossas próprias instituições. Mas, contrariamente a outras filosofias, ele faz isso sem violência" (ZABALA, 2007b, p. 48). Desse modo, a autonomia só pode irromper depois da desconstrução da metafísica e com a emergência da filosofia hermenêutica a expandir o horizonte de possibilidades da liberdade humana e da própria possibilidade de realização da filosofia na pós-modernidade.

Segundo Vattimo tal pensamento corresponde, na perspectiva religiosa, ao fenômeno da secularização enquanto dessacralização da cultura ocidental, não restrita apenas ao solo europeu. Desse modo, “[...] pensamento mais consciente dos limites, que abandona as pretensões das grandes visões metafísicas globais, etc; mas sobretudo teoria do enfraquecimento como característica constitutiva do ser na época do fim da metafísica" (VATTIMO, 1999, p. 25-26). Tal pensamento expressa o fim da metafísica e a constatação de que ao final, positivamente o que nos resta é o niilismo. Liga-se, portanto, intrinsecamente à morte de Deus, à perda da verdade, à secularização, como se pode depreender ao longo do presente percurso.

Assim sendo, pode-se afirmar que a filosofia de Gianni Vattimo caracterizase por filosofia interpretativa da cultura ocidental sob o crivo do enfraquecimento (indebolimento) das estruturas estáveis do ser, traduzida numa ontologia débil ou ontologia do declínio ${ }^{12}$, segundo a qual o período pós-moderno corresponde positivamente ao momento em que de modo contraditório e ambíguo se aborda o ser debilitado enquanto evento, acontecimento efêmero, essência imersa na

\footnotetext{
${ }^{12}$ Para Vattimo (2002, p. VIII), “A ontologia nada mais é que interpretação da nossa condição ou situação, já que o ser não é nada fora do seu 'evento', que acontece no seu e nosso historicizar-se".
} 
temporalidade. Vattimo nomeia e desenvolve tal hermenêutica ontológica como ontologia da atualidade, compreendida como discurso que busca esclarecer o significado do ser na situação presente (VATTIMO, 2003, p. 15). Aqui atualidade apresenta o sentido de referência à condição comum da vida atual. A ontologia da atualidade intenta promover o enfraquecimento dos ideais fundacionais da metafísica, ou seja, levar a cabo a dissolução da própria metafísica. Tal ontologia apresenta dúplice sentido: o de dar-se conta dos paradigmas nos quais nos encontramos lançados; via de suspensão da pretensão de validade desses paradigmas em favor de uma escuta do ser enquanto acontecimento histórico não dito (VATTIMO, 2009, p. 45). À luz de Walter Benjamim, Vattimo identifica tal escuta do ser como atenção à voz dos perdidos da história. Por isso, tal ontologia pode ser compreendida como pensamento dos fracos ou oprimidos pelo sistema.

Em consonância com a ontologia da atualidade, a grande característica do pensiero debole a estremecer as grandes instituições e hierarquias governamentais reside na defesa da falta de fundamento e de verdades absolutas. Pensamento aberto à heterogeneidade de racionalidades e propício ao diálogo com o mundo contemporâneo.

Nesses termos Santiago Zabala, discípulo de Vattimo, classifica o pensiero debole:

O pensamento fraco não é outra coisa do que o conhecimento, a aceitação e o reconhecimento de que a filosofia, após a desconstrução da metafísica, não pode apreender a essência última de seus objetos, mas precisa aquiescer a uma multiplicidade de interpretações. (ZABALA, 2009, p. 121).

Desse modo, na perspectiva pós-metafísica o pensiero debole se empenha na superação da verdade única, mediante a distorção/enfraquecimento das categorias objetivantes da metafísica. Cabe destacar o fato de a superação da metafísica implicar não o derradeiro abandono desta, mas o ato de debruçar-se 
sobre si mesma, a atitude de rimettersi (Verwindung) ${ }^{13}$ à própria metafísica como algo que lhe é destinado. A lógica do pensiero debole se demonstra tanto menos violenta e mais tolerante que a metafísica tradicional, por proclamar como verdade objetiva, a diversidade de interpretações da realidade. Para os niilistas reativos, pensamento qualificado como fomento ao relativismo, ao subjetivismo e ao individualismo. Para os niilistas consumados, pensamento aberto à relatividade, afinado com a hermenêutica gadameriana e propício à irrupção de uma sociedade mais propensa ao diálogo e favorável à emancipação das minorias.

Constatar em Vattimo o pensiero debole como núcleo constitutivo da ontologia da atualidade ou via privilegiada de interpretação da cultura contemporânea implica ir além da simples afirmação do fim da metafísica e do advento do niilismo (VATTIMO; PATERLINI, 2006, p. 126). ${ }^{14}$ Evoca considerar a história do Ocidente, desde os primórdios da filosofia grega, como história do esquecimento do ser. Positivamente, história da passagem das pretensões absolutas à situação segundo a qual a possibilidade de existência da verdade sugere dinamismo consensual. Desse modo, sobre o conceito de interpretação Vattimo (2009, p. 73) esclarece: “[...] não há experiência da verdade que não seja interpretativa, eu não conheço nada se não me interessa, mas se me interessa é evidente que não o considero de modo desinteressado”.

A fundamentação teórica do pensiero debole entrelaça-se à constatação do processo de secularização ocorrido sobretudo ao longo dos séculos XVIII e XIX. Tal tendência secularizante faz-se presente na cultura ocidental e não se restringe unicamente ao universo europeu (ROMANO, 2010, p. 13).15 Na perspectiva filosófica, esse processo culmina na perda da ideia da filosofia como racionalidade

\footnotetext{
${ }^{13}$ Ao falar sobre a condição de superação da metafísica, Heidegger utiliza o termo Verwindung, traduzido por Vattimo por rimettersi, considerando os sentidos da palavra em italiano: restabelecer-se, sarar de uma doença, remeter-se a algo ou a alguém. $O$ estado de convalescência implicado apresenta imagem bem clara para se compreender tal situação, pois ainda que o doente não se encontre mais tomado pela enfermidade, tampouco dela completamente se libertou. Neste caso, situa-se num momento de passagem e o alcance da cura pressupõe o reconhecimento e a vivência da enfermidade cujos traços ainda se fazem presentes. Ademais, a vivência da enfermidade transforma e modifica o mundo do sujeito, mesmo após a cura.

${ }^{14}$ É a partir do estudo de Gadamer que Vattimo apreende cada experiência da verdade como experiência interpretativa, um tema desenvolvido mais por seu mestre Luigi Pareyson que pelo próprio Gadamer.

${ }^{15}$ Para o filósofo Roberto Romano a corrosão "de alto a baixo" no caráter de indivíduos e grupos, bem como a supervalorização do mercado são traços peculiares do niilismo em terras brasileiras.
} 
fundacional. Acerca da atualidade de tal pensamento, na tarefa de interpretar e traduzir a realidade da cultura contemporânea, Vattimo atesta:

E, porém, uma das provas de que o pensamento fraco ainda está vivo pode ser vista exatamente no fato de que a exigência de 'pensamento forte' ainda vem sendo continuamente reivindicada por setores mais diversos, usualmente por pessoas ou grupos que sentem a necessidade de alguma 'restauração': da autoridade da Igreja, por exemplo [...]. (VATTIMO, 2008, p. 10). ${ }^{16}$

Para além das contradições constitutivas do pensiero debole, bem como das acusações a ele desferidas, prevalece a instigante proposta hermenêutica vattimiana nesse percurso compreendida positivamente como limite às pretensões violentas do pensamento único. Postura filosófica capaz de questionar o status quo da cultura dominante e de promover a coexistência pacífica em meio à diversidade. O sujeito debilitado é mais tolerante, aberto aos outros (VATTIMO, 2010, p. 6). Por sua vez, coexiste o risco da afirmação de novo absoluto negativo: o niilismo. Para fugir das malhas desse perigo Vattimo adverte que compete ao pensiero debole garantir a contínua abertura histórica e não a legitimação de nova ordem metafísica. Por isso, a grande "verdade" do pensiero debole não pode ser expressa na ideia da não existência da verdade. Antes, deve ser pensada mediante a afirmação de seu constante enfraquecimento. A afirmação do enfraquecimento da verdade nutre o questionamento presente junto à ação do ser humano se relacionar com o mundo no campo das artes, da política, da tecnologia, das religiões e da sociedade como um todo, uma vez que a ausência do fundamento incide diretamente sobre o valor atribuído às vivências cotidianas.

Tal dimensão niilista presente na ontologia da atualidade proposta por Vattimo, da qual o pensiero debole é a máxima expressão, encontra seus germes no legado da secularização cristã a tecer a cultura ocidental.

\footnotetext{
${ }^{16}$ No mesmo artigo à p. 16 o autor enaltece o destino de enfraquecimento do pensamento e pondera: "Visando o próprio
} enfraquecimento, o pensamento tem ainda muito caminho a percorrer e nesse sentido continua a ser de plena atualidade". 


\section{A vocação niilista da hermenêutica radicada no processo da secularização cristã}

"Todos os fenômenos de secularização da modernidade enquanto dessacralização do sagrado são herança do cristianismo" (VATTIMO; PATERLINI, 2006, p. 182).

O pensar de Vattimo apresenta conexão intrínseca com a experiência cristã católica vivida pelo autor. A pergunta acerca dos traços constitutivos da herança cristã a perpassarem a cultura ocidental acompanhará a obra do filósofo e constitui fio condutor para se compreender o discurso proposto. A adesão de Vattimo ao cristianismo remete à sua frequência constante à paróquia, durante a infância, bem como à educação marcada pelo acento cristão católico. Os valores cristãos compuseram o horizonte modelar de atitudes e grande fomento ao interesse social que marcaram o período de formação do jovem Vattimo. A geografia italiana, significativamente regida sob a égide da moralidade do báculo do sumo pontífice, afetou existencialmente a compreensão de Vattimo acerca das relações sociais, políticas e humanas. Desde jovem o autor relata ter sofrido o peso da moralidade católica cristã, em função de sua homossexualidade. Fato que o motivou a divergir não da racionalidade da mensagem cristã (da qual se considera devedor), mas do conteúdo da moralidade defendida pela estrutura hierárquica eclesiástica.

Na afirmação do próprio autor, a dedicação ao estudo da filosofia se dá no intuito de se

contribuir para a formação de um novo humanismo cristão, livre tanto do individualismo liberal, quanto do coletivismo e do determinismo marxista. Foi na época em que nós, jovens católicos, estudávamos as obras de Jacques Maritain [...] De Maritain herdei a desconfiança em relação a certos dogmas da modernidade [...]. (VATTIMO, 2004, p. 8-9).

Na busca de estabelecer o diálogo provocativo entre cristianismo e filosofia alguns temas são recorrentes nos escritos do autor, dentre os quais sobressaem a herança cristã do niilismo e a encarnação do Verbo versus secularização. O 
declínio da metafísica enquadra-se nessa perspectiva, pois quanto mais secularizado o mundo se encontra, tanto menos há necessidade de se perguntar por uma vida após a morte ou pela finalidade última da vida, ou seja, por uma instância transcendente a garantir a ordem natural do mundo. O destino de enfraquecimento do ser encontra suas raízes últimas na constatação do cristianismo como mensagem a difundir a secularização como destino. Isto porque, a afirmação do pensiero debole implica o reconhecimento de que sua elaboração teórica se dá a partir da compreensão do processo de secularização em marcha.

O termo secularização apresenta basicamente dois sentidos: jurídico (passagem de pessoas do estado clerical para o secular, ou a passagem de bens eclesiásticos a propriedade secular) e cultural:

O significado cultural do conceito é mais tardio e só se forma por volta do final do século XX, para indicar o processo de emancipação da vida cultural (política, ciência, economia, literatura, filosofia, arte e costumes) da tutela eclesiástica [...]. Nesta acepção cultural, o termo 'secularização' indica, de um lado, o processo de emancipação do mundo moderno da tutela do cristianismo e da Igreja (momento de descontinuidade); mas de outro lado, remete à contribuição do cristianismo para a formação do mundo moderno e à permanência de impulsos cristãos na sociedade moderna (momento de continuidade). (GIBELLINI, 2002, p. 123).

\section{Vattimo compreende a secularização como a}

perda da autoridade temporal por parte da Igreja, conquista da autonomia da razão humana frente a dependência de um Deus absoluto, juiz ameaçador e [...] efeito positivo do ensinamento de Jesus [...] $\mathrm{O}$ sentido 'positivo' de secularização, isto é, a ideia que a modernidade laica se constitui também e sobretudo como interpretação dessacralizante da mensagem bíblica [...]. (VATTIMO, 1999, p. 34).

A secularização remete ainda ao conceito kênosis extraído da tradição bíblica. O célebre hino presente na carta de Paulo aos Filipenses, atesta a atitude de auto-enfraquecimento do Deus cristão: "Mas esvaziou-se a si mesmo, e assumiu a condição de servo, tomando a semelhança humana” ( $F l$ 2,7). Nesse horizonte, a perspectiva adotada por Vattimo propõe a kênosis como evento não violento da 
ação de Deus, em oposição à violência característica da metafísica. Assim destaca o filósofo:

É a encarnação do Filho de Deus que nos libertou do poder da 'verdade' em nome da qual se pode perseguir, condenar à fogueira, promover guerras de religião e cruzadas. É verossímil que o pensamento fraco declare que a verdade é Jesus Cristo e só ele? É, enquanto o que Jesus Cristo prega é o abandono dos ídolos - começando por aqueles que a 'razão' descobriria como seus inegáveis fundamentos - em prol de uma relação pessoal com o outro. (VATTIMO, 2008, p. 14).

A kênosis iniciada com a encarnação de Cristo continua a realizar-se em termos sempre mais claros, prosseguindo a obra de educação do ser humano à superação da originária essência violenta do sagrado e da mesma vida social. Tais considerações iluminam a compreensão da positividade conferida por Vattimo à secularização:

Secularização como fato positivo significa que a dissolução das estruturas sacrais da sociedade cristã, a passagem a uma ética da autonomia, à laicidade do estado, a uma menos rígida literalidade na interpretação dos dogmas e dos preceitos, não corresponde à despedida do cristianismo, mas a mais plena realização da sua verdade que é, recordemos, a kênosis, o abaixamento de Deus, a negação dos traços 'naturais' da divindade. (VATTIMO, 1999, p. 40, grifo no original).

A obra de Vattimo Credere di credere estabelece o pertinente nexo entre a corrente hermenêutica niilista e a tradição cristã da caridade, humildade e kênosis. Nela o autor demonstra que a hermenêutica e o niilismo se convertem em opções éticas, ao invés de ocupar o papel de inimigos morais (GRONDIN, 2007, p. 240). Para Vattimo (2009, p. 60), a mais íntima vocação e possibilidade de realização do cristianismo se encontra na caridade: "Hoje os cristãos são chamados a dissolver dogmatismos e autoritarismos em favor de uma atenção caridosa a todos". Tal convite advém do retrair -se de Deus a traduzir a atitude inaugurante da relativização, do enfraquecimento da ordem natural pré-estabelecida em detrimento da valorização do mundo. Daí: 
A ontologia hermenêutica (que tematiza explicitamente a produtividade da interpretação) e o fim da metafísica da presença como êxito da ciência técnica moderna resultaram da ação da mensagem cristã na história da civilização ocidental; são interpretações secularizantes dessa mensagem, mas em um sentido positivo-construtivo do termo. Seria necessário acrescentarmos aqui que a secularização não é um termo que se choque com a essência da mensagem e sim um aspecto constitutivo: como evento salvífico e hermenêutico, a encarnação de Jesus (a kênosis, o rebaixamento de Deus) é ela mesma, acima de tudo, um fato arquetípico da secularização. (VATTIMO, 2004, p. 85-86).

Vattimo reflete positivamente a secularização como herança do cristianismo, momento interno e essencial da experiência religiosa, bem como sustenta a difusão de seus veios pela filosofia e pela cultura atual, o que se faz notar mediante a crise das ideologias, a dissolução da metafísica e a perda do sentido da história como processo unitário (VATTIMO, 1987, p. V). Do já exposto, se depreende a "vertente cristã" a perpassar a formulação do pensiero debole. A própria noção de uma história aberta e não "já dada", herança do pensar de Joaquim de Fiore, inspira o percurso vattimiano de compreensão da história como lugar das possibilidades do evento do ser. A convergência entre filosofia e cristianismo reflete a apropriação filosófica da verdade da religião a difundir a matriz kenótica cristã, a qual escoa pela cultura ocidental por meio da secularização:

Se contudo, a secularização é o modo pelo qual se atua o enfraquecimento do ser, ou seja, a kénosis de Deus, que é o cerne da história da salvação, ela não deverá ser mais pensada como fenômeno de abandono da religião, e sim como atuação, ainda que paradoxal, da sua íntima vocação. (VATTIMO, 2004, p. 35, grifo no original).

Deste cenário deriva o que se compreende por ontologia niilista enquanto herdeira da crença cristã na encarnação de Deus, a qual se dá plenamente na história e tem na própria história a condição de possibilidade de sua realização. Nessa perspectiva, Vattimo considera a novidade do pensamento do século XX, e sobretudo de Heidegger, a constatação de que as estruturas que Kant considerava 
iguais para a razão em todos os tempos e lugares, são elas mesmas eventos histórico-destinais (VATTIMO, 1995). ${ }^{17}$

Heidegger, pelo contrário, reclama a necessidade de 'se esquecer do ser como fundamento' se queremos alcançar o pensamento rememorador [...]. Já em Ser e tempo, o ser é 'esquecido como fundamento'; no lugar do ser capaz de funcionar como Grund se percebe - precisamente na centralidade que assume a analítica existencial e a elucidação do nexo com o tempo - um 'ser' que, constitutivamente, não é capaz de fundar, um ser débil e despotenciado. (VATTIMO, 1995, p. 50-51).

O pensamento de Vattimo transita dentro do horizonte do niilismo e oferece as bases para a elaboração de uma hermenêutica sem pretensões de alcance de um fundamento ou de uma verdade. Ainda que se possa afirmar, a partir da leitura de Nietzsche e de Heidegger, que pensar significa fundamentar, tal "fundamentação" no caso de Vattimo deve ser considerada em sentido hermenêutico enquanto possibilidade desfundante (e não de fundação/fundamentação), uma vez que a ontologia da atualidade se compromete com a ruptura das estruturas fortes do ser, como se buscou demonstrar.

\section{Conclusão}

Constata-se o crescente empenho de instituições e Estados em prol do retorno dos parâmetros e princípios ancorados nos ideais do pensamento forte e, desse modo, pouco afeitos à conversação e ao encontro com outras possíveis alteridades ou outros modos de ser. Tal fato se faz notar, por exemplo, nos discursos unilaterais invocados no intuito de legitimar determinadas ações, como foi o caso do então presidente Bush ao justificar a invasão ao Iraque baseado na afirmação da existência de armas químicas de destruição em massa (SACONI; ENTINI, 2013). Em nome da pretensão de determinada razão absoluta, guerras e atrocidades são cometidas. Na contramão dessa perspectiva se enquadra o grande

\footnotetext{
${ }^{17}$ Sobre a reflexão de Heidegger referente ao esquecimento do ser como fundamento, Vattimo remete a Heidegger, 1969, p. 5-6. : HEIDEGGER, M. Zur sache des denkens. Niemeyer: Tubinga, 1969. p. 5-6.
} 
papel da hermenêutica filosófica para a atualidade, dado seu caráter democrático e contrário à imposição da verdade. Hermenêutica a exaltar a natureza interpretativa das descrições a permear a realidade.

Em termos pós-modernos, a política ao invés de assegurar a manutenção da "verdade" dominante, deve guiar-se pela escuta das verdades apregoadas pelas minorias, no intuito de promover a conversação entre estas, na constante abertura para a reinterpretação da racionalidade em voga. Desse modo se pode pensar no alcance de um consenso democrático a partir da promoção da autonomia do sujeito, grande tarefa da ontologia da atualidade. Daí a possibilidade de uma política da interpretação do direito dos fracos, a qual proporciona também aos fracos (os "perdidos da história") o direito de interpretar (VATTIMO; ZABALA, 2012, p. 126-127).

Desse modo, a filosofia hermenêutica desenvolvida por Vattimo reflete o pluralismo das sociedades dispostas a não pautar o alcance de seus objetivos por meio da manutenção e garantia da verdade, mas pela habilidade de relacionar-se com os outros. Aqui não se trata de defender ou exaltar o relativismo, mas de afirmar a possibilidade da vivência da relatividade das relações em jogo, as quais muitas vezes apresentam nuances anárquicas, no sentido de se oporem aos cânones históricos estabelecidos. A validade de tal proposição não se limita ao campo específico da política, mas possui alcance para as demais instituições religiosas e seculares, bem como para as diversas representações e instâncias da sociedade civil.

Para finalizar, importa se perguntar em que medida permanece ainda a hermenêutica como koiné da filosofia e da cultura nos dias de hoje. Diante do exposto acima, compreende-se a relevância da hermenêutica filosófica como instrumento de redução dos mecanismos de violência engendrados pelos sistemas comprometidos com a promoção dos valores absolutos. Aqui se destaca o papel exercido pela herança da secularização cristã, a qual permite à hermenêutica 
valoração positiva do niilismo, bem como do destino de enfraquecimento do ser e lhe confere dinamicidade e abertura para devidamente se compreender a existência humana como interpretação historicamente situada.

\section{REFERÊNCIAS}

ANTISERI, D. Il 'pensiero debole' contro le pretese di una 'ragione onnipotente'. In: ANTISERI, D.; VATTIMO, G. Ragione filosofica e fede religiosa nell'era postmoderna. Rubbettino: Soveria Manelli, 2008. p. 19-21.

BEUCHOT, M.; ARENAS-DOLZ, F. Hermenéutica de la encrucijada: analogía, retórica y filosofía. Barcelona: Anthropos, 2008.

BÍBLIA. Português. A Bíblia de Jerusalém. 7. ed. São Paulo: Paulinas, 1995.

DOTOLO, C. La teologia fondamentale davanti alle sfide del "pensiero debole" di G. Vattimo. Roma: Ateneo Salesiano, 1999.

GADAMER, H-G. Verità e metodo. Tradução Gianni Vattimo. 4. ed. Milano: Bompiani, 2012.

GIBELLINI, R. A teologia do século XX. 2. ed. São Paulo: Loyola, 2002.

GRONDIN, J. La latinización de la hermenéutica de Vattimo: ¿̇por qué Gadamer resistió al postmodernismo? In: ZABALA, S. (ed.). Debilitando la filosofía: ensayos en honor a Gianni Vattimo. Barcelona: Anthropos, 2007. p. 238-252.

HABERMAS, J. Hans Georg Gadamer. In: HABERMAS, J. Perfiles filosóficopolíticos. Madrid: Taurus, 1984. p. 346-354.

HEIDEGGER, M. Ser y tiempo. 3. ed. Madrid: Editorial Trotta, 2012.

HEIDEGGER, M. Zur sache des denkens. Tubinga: Niemeyer, 1969.

LÉVINAS, E. Totalidade e infinito. Lisboa: Ed. 70, 2000.

LIPOVETSKY, G. Futuro da autonomia e sociedade do indivíduo. In: NEUTZLING, I.; BINGEMER, M. C.; YUNES, E. (org.). O futuro da autonomia: uma sociedade de indivíduos? São Leopoldo/Rio de Janeiro: Unisinos, Ed. PUC Rio, 2009. p. 59-71.

LYOTARD, J. F. A condição pós-moderna. 8. ed. Rio de Janeiro: José Olympio, 2002.

REALE, G. La presenza di Platone in "Verità e metodo" di Hans-Georg Gadamer. In: GADAMER, H-G. Verità e método. 4. ed. Milano: Bompiani, 2012. p. VII-XXIV. 
RICOEUR, P. L'herméneutique biblique. Paris: Du Cerf, 2001.

RICOEUR, P. Teoría de la interpretación: discurso y excedente de sentido. México: Siglo XXI, 1995.

RISSER, J. Sobre la continuación de la filosofía: la hermenéutica como convalecencia. In: ZABALA, S. (ed.). Debilitando la filosofía: ensayos en honor a Gianni Vattimo.

Barcelona: Anthropos, 2007. p. 217-237.

ROMANO, R. Niilismo e mercadejo ético brasileiro. "Niilismo e relativismo de valores. Mercadejo ético ou via da emancipação e da salvação”? Revista do Instituto Humanitas Unisinos, São Leopoldo, ano X, n. 354, p. 13-17, 20 dez. 2010.

SACONI, R.; ENTINI, C. E. Com justificativa falsa, Iraque era invadido há 10 anos. Estado de S. Paulo, São Paulo, 19 mar. 2013. Disponível em: <http://acervo.estadao.com.br/noticias/ acervo,com-justificativa-falsa-iraque-erainvadido-ha-10-anos,8951,o.htm>. Acesso em: 01 jan. 2015.

VATTIMO, G. (org.). Filosofia 86. Roma/Bari: Laterza, 1987.

VATtimo, G. A tentação do realismo. Rio de Janeiro: Nova Aguilar, 2001.

VATTIMO, G. Addio alla verità. Roma: Meltemi, 2009.

VATTIMO, G. Credere di credere: è possibile essere cristiani nonostante la Chiesa? 2. ed. Roma: Garzanti, 1999.

VATTIMO, G. Depois da cristandade: por um cristianismo não religioso. Rio de Janeiro: Record, 2004.

VATTIMO, G. Diálogo com Nietzsche. São Paulo: Martins Fontes, 2010.

VATTIMO, G. Ética de la interpretación. Barcelona: Paidós, 1991.

VATTIMO, G. Más allá de la interpretación. Barcelona: Paidós, 1995.

VATTIMO, G. Más allá del sujeto: Nietzsche, Heidegger y la hermenéutica. Barcelona: Paidós, 1989.

VATTIMO, G. Morte de Deus e o fim da metafísica: a luta contra os absolutos. Revista do Instituto Humanitas UNISINOS, São Leopoldo, ano X, n. 354, p. 5-7, dez. 2010.

VATTIMO, G. Nichilismo ed emancipazione: etica, politica, diritto. Varese: Garzanti, 2003.

VATTIMO, G. O fim da modernidade: niilismo e hermenêutica na cultura pósmoderna. 2. ed. São Paulo: Martins Fontes, 2002. 
VATTIMO, G. O que está vivo e o que está morto no pensamento fraco. In: PECORARO, R. (org.). Filosofia contemporânea: niilismo, política, estética. São Paulo: Loyola, 2008. p. 9-16.

VATTIMO, G. Per un cristianesimo non religioso. In: FILORAMO, G.; GENTILE, E.; VATTIMO, G. Cos'è la religione oggi? Pisa: ETS, 2005. p. 43-61.

VATTIMO, G. Schleiermacher: filosofo dell’interpretazione. 2. ed. Milano: Mursia, 1986.

VATTIMO, G.; PATERLINI, P. Non essere Dio: un'autobiografia a quattro mani. Reggio Emilia: Aliberti Editore, 2006.

VATTIMO, G.; ROVATTI, P. A. Il pensiero debole. Milano: Feltrinelli, 1983.

VATTIMO, G.; ZABALA, S. Comunismo hermenéutico: de Heidegger a Marx. Barcelona: Herder, 2012.

VOLPI, F. Il nichilismo. Roma: Laterza, 2009.

ZABALA, S. (ed.). Debilitando la filosofía: ensayos en honor a Gianni Vattimo. Barcelona: Anthropos, 2007a.

ZABALA, S. Entrevista. O pensamento fraco é a emancipação da autonomia. São Leopoldo, 21 maio 2007b. Disponível em:

<http://www.ihuonline.unisinos.br/index.php?option=com_co

ntent\&view=article\&id=947\&secao=220 > . Acesso em: 14 abr. 2009.

ZABALA, S. Ser fraco: a constituição autônoma do Übermensch. In: NEUTZLING, I.; BINGEMER, M. C.; YUNES, E. (org.). O futuro da autonomia: uma sociedade de indivíduos? Rio de Janeiro: Ed. PUC-Rio; São Leopoldo: Unisinos, 2009. p. 121-130. 